\title{
A case study of gravity wave dissipation in the polar MLT region using sodium LIDAR and radar data
}

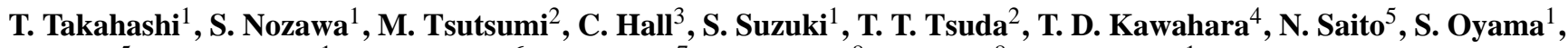

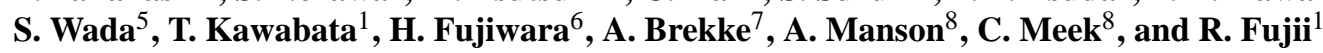 \\ ${ }^{1}$ Solar-Terrestrial Environment Laboratory, Nagoya University, Nagoya, Aichi, Japan \\ ${ }^{2}$ National Institute of Polar Research, Tachikawa, Tokyo, Japan \\ ${ }^{3}$ Troms $\varnothing$ Geophysical Observatory, University of Troms $\varnothing$, Troms $\varnothing$, Norway \\ ${ }^{4}$ Faculty of Engineering, Shinshu University, Nagano, Nagano, Japan \\ ${ }^{5}$ RIKEN Center for Advanced Photonics, RIKEN, Wako, Saitama, Japan \\ ${ }^{6}$ Faculty of Science and Technology, Seikei University, Musashino, Tokyo, Japan \\ ${ }^{7}$ Faculty of Science, University of Troms $\varnothing$, Troms $\varnothing$, Norway \\ ${ }^{8}$ Institute of Space and Atmospheric Studies, University of Saskatchewan, Saskatoon, Saskatchewan, Canada \\ Correspondence to: T. Takahashi (ttohru@stelab.nagoya-u.ac.jp)
}

Received: 6 July 2014 - Accepted: 1 September 2014 - Published: 7 October 2014

\begin{abstract}
This paper is primarily concerned with an event observed from 16:30 to 24:30 UT on 29 October 2010 during a very geomagnetically quiet interval $(\mathrm{Kp} \leq 1)$. The sodium LIDAR observations conducted at Troms $\varnothing$, Norway $\left(69.6^{\circ} \mathrm{N}, 19.2^{\circ} \mathrm{E}\right)$ captured a clearly discernible gravity wave $(\mathrm{GW})$ signature. Derived vertical and horizontal wavelengths, maximum amplitude, apparent and intrinsic period, and horizontal phase velocity were about $\sim 11.9 \mathrm{~km}$, $\sim 1.38 \times 10^{3} \mathrm{~km}, \sim 15 \mathrm{~K}, 4 \mathrm{~h}, \sim 7.7 \mathrm{~h}$, and $\sim 96 \mathrm{~m} \mathrm{~s}^{-1}$, respectively, between a height of 80 and $95 \mathrm{~km}$. Of particular interest is a temporal development of the uppermost altitude that the GW reached. The GW disappeared around $95 \mathrm{~km}$ height between 16:30 and 21:00 UT, while after 21:00 UT the GW appeared to propagate to higher altitudes (above $100 \mathrm{~km}$ ). We have evaluated three mechanisms (critical-level filtering, convective and dynamic instabilities) for dissipations using data obtained by the sodium LIDAR and a meteor radar. It is found that critical-level filtering did not occur, and the convective and dynamic instabilities occurred on some occasions. MF radar echo power showed significant enhancements between 18:30 and 21:00 UT, and an overturning feature of the sodium mixing ratio was observed between 18:30 and 21:20 UT above about $95 \mathrm{~km}$. From these results, we have concluded that the GW was dissipated by wave breaking and instabilities before 21:00 UT. We have also investigated the difference of the background atmosphere for
\end{abstract}

the two intervals and would suggest that a probable cause of the change in the GW propagation was due to the difference in the temperature gradient of the background atmosphere above $94 \mathrm{~km}$.

Keywords. Meteorology and atmospheric dynamics (waves and tides)

\section{Introduction}

Gravity waves (GWs) propagating upward usually dissipate in the upper mesosphere and (partly) lower thermosphere (MLT) region, and their energy and momentum release through dissipation plays a dominant role in the zonal mean wind reversal as well as in meridional circulation in the upper mesosphere (Lindzen, 1981; Holton, 1982). GW propagation depends on background thermodynamics and wind dynamics (Fritts and Alexander, 2003). Dissipation of GWs mainly results from wave breaking and instabilities, wavewave and wave-mean flow interactions, and radiative damping (Lu et al., 2009). GWs that are not otherwise attenuated by ambient turbulence, wave-wave interactions, and the like will eventually break down owing to instabilities that the waves themselves generate (Hecht et al., 1997). Instabilities generated by GWs may be convective and/or dynamical (shear) instabilities. There is an issue concerning how 
GWs can penetrate into the thermosphere without having significant dissipation in the mesosphere. Some model studies pointed out that GWs can propagate into the thermosphere (e.g., Vadas and Fritts, 2004; Fritts and Vadas, 2008). Conditions of upward propagation of GWs through the mesosphere into the thermosphere have not yet been investigated well based on observations. In particular, there are fewer studies conducted in the polar MLT region, which has another energy source from the magnetosphere, than those at middle and low latitudes. It is important to understand the relationship between upward propagation of GWs and background thermodynamics/wind dynamics in the polar MLT region for further understanding of the lower-thermosphere dynamics, variabilities of the ionosphere, and the magnetosphere-ionospherethermosphere coupling process.

Dynamical and convective instabilities are two mechanisms that contribute significantly to the dissipation of largerscale motions and the generation of turbulence in the middle atmosphere (Fritts and Rastogi, 1985). Recent observations using an $\mathrm{OH}$ airglow imager and a sodium LIDAR showed that wave breaking occurred and the subsequent appearance of ripples was related to dynamical (or KelvinHelmholtz) instabilities (Li et al., 2005; Hecht et al., 2005). Hodges Jr. (1967) pointed out that GWs can produce convective instabilities in thin layers that propagate with the waves and then generate turbulence. Hodges Jr. (1967) also stated that wind shears, which are strong enough to produce regions in which the Richardson number $(R i)$ is less than 1 , often exist and that these may possibly be important in sustaining turbulence. One of the dynamical instabilities in the atmosphere is the Kelvin-Helmholtz (KH) instability, which sets in when the Richardson number of the wind profile is less than 0.25 (Drazin, 1958). Because KH instabilities can achieve large amplitudes and kinetic energies, they can have a number of important effects, including the excitation of other wave motions, the local transport of momentum and energy, and the generation of turbulence and diffusion (Fritts and Rastogi, 1985). On the other hand, the most obvious regions of convective instability occur in the upper stratosphere, mesosphere, and lower thermosphere due to the growth of wave amplitude with height increasing. The depths of these layers are typically about $3-10 \mathrm{~km}$ in the MLT region, suggesting that dominant vertical wavelengths are more than twice these values (Fritts and Rastogi, 1985). Based on wind observations by middle- and upper-atmosphere (MU) radar at Shigaraki $\left(34.9^{\circ} \mathrm{N}, 136.1^{\circ} \mathrm{E}\right)$ and temperature from the COSPAR International Reference Atmosphere (1972) model, Yamamoto et al. (1987) found a monochromatic inertia gravity wave and showed clear evidence that gravity waves were saturated, induced the shear or convective instabilities, and generated turbulence in the mesosphere. $\mathrm{Li}$ et al. (2005) reported the breakdown of a high-frequency quasi-monochromatic gravity wave into small-scale ripples based on $\mathrm{OH}$ airglow data obtained in Maui, Hawaii. They concluded that the breakdown was caused by dynamical (or
Kelvin-Helmholtz) instabilities. Although numerous studies have been carried out, there are not many studies published that deal with dissipation of GWs of longer periods $(\geq \sim 4 \mathrm{~h})$ based on observational data of temperature and wind.

In this paper, we have investigated the dissipation process of a GW in the polar MLT region based on temperature, wind, and echo power data obtained with the sodium LIDAR, meteor radar (hereafter, MR), and MF (medium frequency) radar, respectively, operated at the same observational field: Ramjordmoen, Troms $\varnothing$, Norway $\left(69.6^{\circ} \mathrm{N}, 19.2^{\circ} \mathrm{E}\right)$. The $3 \mathrm{~h}$ Kp index was 1, 0, 0, and 0 between 15:00 UT on 29 October and 03:00 UT on 30 October 2010, indicating that auroral effects are negligible. In Sect. 2, we will describe the instruments used in this study. In Sect. 3, observational results will be shown. In Sect. 4, mechanisms for the dissipation of the GW are investigated and discussed. Furthermore, the difference in the background atmosphere between the two intervals (16:30-21:00 and 21:00-24:30 UT) is investigated. This paper ends with a summary in Sect. 5 .

\section{Instruments}

\subsection{Sodium LIDAR}

The sodium LIDAR at Troms $\varnothing$ has a stable laser unit and five sets of telescopes ( $355 \mathrm{~mm}$ diameter Schmidt-Cassegrain) and receivers. The laser unit consists of an all-solid state Q-switched single-frequency source tuned to the sodium D2-a line at $589.1583 \mathrm{~nm}$. The source is based on sumfrequency mixing of two injection-locked Nd:YAG lasers in $\mathrm{LiB}_{3} \mathrm{O}_{5}$, which were used under $90^{\circ}$ phase-matching conditions at a temperature of $39.5^{\circ} \mathrm{C}$. Transmitted laser power was $\sim 1.8 \mathrm{~W}$ for the night of 29 October 2010 . Photons returned from the sodium layer and collected by the receiving telescopes were integrated for $5 \mathrm{~s}$. Due to hardware problems, only three receivers were utilized for the night, and the three telescopes were pointed in a vertical direction. Under a twofrequency mode used to derive a neutral temperature (cf. She et al., 1990; She and Yu, 1995), we changed the frequency every $2 \mathrm{~min}$. An optical filter with $3 \mathrm{~nm}$ bandwidth was employed. More information on the sodium LIDAR system at Troms $\emptyset$ is found in Nozawa et al. (2014).

\subsection{Meteor radar and MF radar}

The MR (Hall et al., 2005) installed in 2003 in Ramjordmoen can continually provide neutral wind velocity data with $2 \mathrm{~km}$ altitude and $1 \mathrm{~h}$ time resolution from approximately 80 to $100 \mathrm{~km}$. This radar system operates at $30.25 \mathrm{MHz}$. The field of view of this radar is about $140^{\circ}$, i.e. a spatial averaging over perhaps $200 \mathrm{~km}$ at the peak echo occurrence height. Descriptions of the determination of wind velocity may be found, for example, in Aso et al. (1979) and Tsutsumi et al. (1999). 
(a)

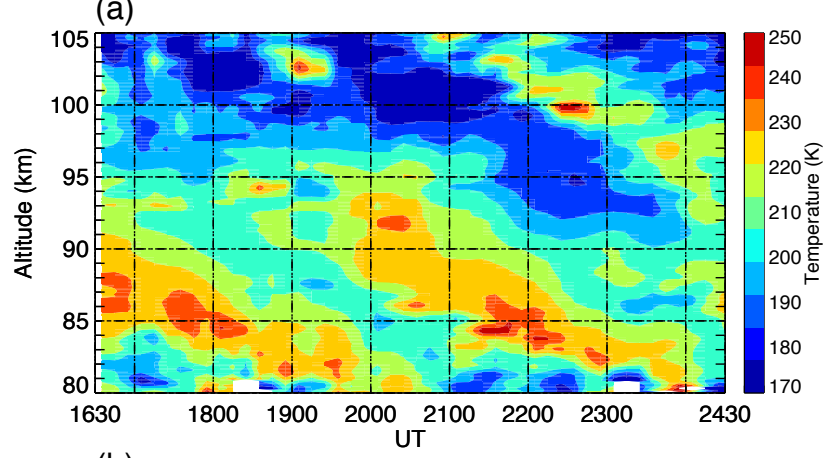

(b)

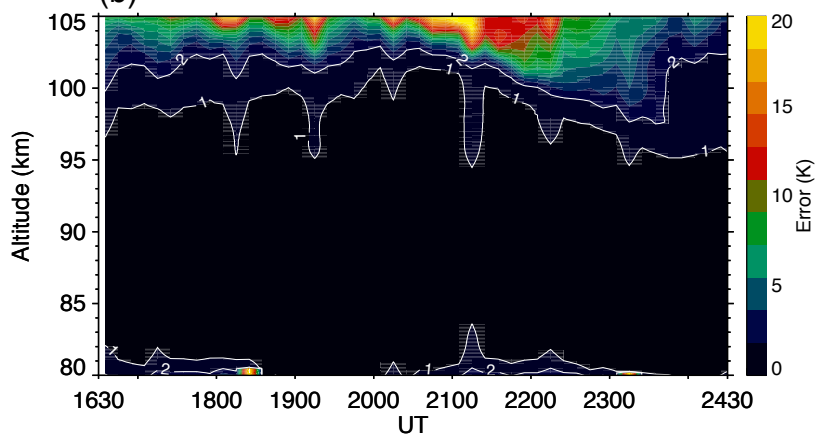

Figure 1. (a) The neutral temperature variation from 16:30 UT on 29 October to 00:30 UT on 30 October 2010. The warmer color indicates higher temperature and colder color indicates lower temperature. The original temporal and altitude resolution is $10 \mathrm{~min}$ and $1.2 \mathrm{~km}$, respectively, and a $30 \mathrm{~min}$ running average is applied. (b) The corresponding error values of the temperature.

The Troms $\varnothing$ MF radar has been in operation for more than 20 years in a spaced-antenna (wind measuring) mode (see, e.g., Meek, 1980; Reid, 1996). A recent specification of this radar can be found in Hall (2001). The Troms $\emptyset$ MF radar operating at $2.78 \mathrm{MHz}$ has continually provided wind data together with echo power in the height region of $\sim 70$ to $\sim 100 \mathrm{~km}$ in so-called "virtual" height. As a result of group retardation, the true heights of the reflections are somewhat lower, particularly for heights above $90 \mathrm{~km}$ (Hall, 2001). The time resolution is usually $5 \mathrm{~min}$.

\section{Observational results}

Figure 1a shows temporal and altitudinal variations of the neutral temperature observed with the sodium LIDAR from 16:30 UT on 29 October 2010 to 00:30 UT on 30 October 2010. To increase the signal-to-noise ratio, we have applied time integration of $10 \mathrm{~min}$ and smoothing to the height with a von Hann (Hanning) window of $1.2 \mathrm{~km}$ resolution. Corresponding error values are shown in Fig. 1b. The error values are less than $2 \mathrm{~K}$ for most instances below $\sim 101 \mathrm{~km}$, while the error values reached about $10-20 \mathrm{~K}$ at $105 \mathrm{~km}$. From Fig. 1a, we can identify that a higher temperature region lowered with time during the observational interval

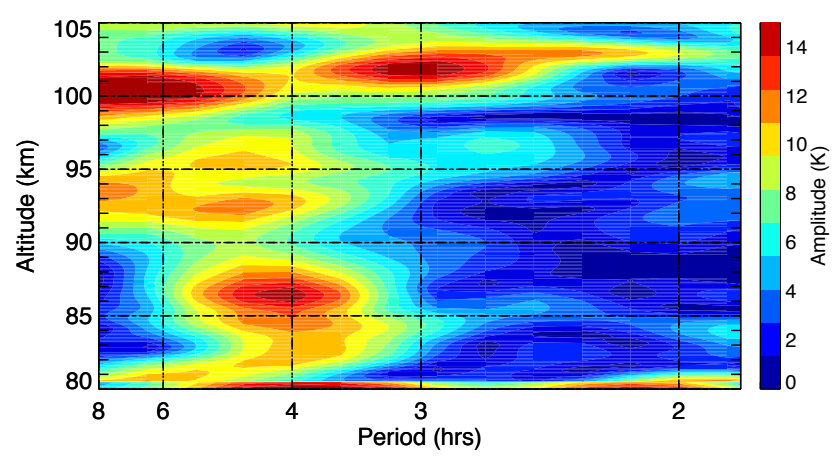

Figure 2. Periodogram as a function of altitude for the neutral temperature variation derived from the Lomb-Scargle method with oversampling factor 4 .

between 80 and $95 \mathrm{~km}$. For example, the higher-temperature (about $230 \mathrm{~K}$ ) region was seen at about $92 \mathrm{~km}$ at 20:00 UT and moved down to about $82 \mathrm{~km}$ at 23:00 UT. These temporal and altitude variations of the temperature suggest the signature of a monochromatic gravity wave (GW) propagating upward. On the other hand, no periodical temperature variation can be seen above $95 \mathrm{~km}$ between 16:30 and 21:00 UT, while a similar (but weaker) temperature variation can be found above $95 \mathrm{~km}$ from 21:00 to 24:30 UT. This difference suggests that conditions of the background atmosphere changed and affected the propagation of the GW.

Figure 2 shows contours of spectra of the neutral temperature from 80 to $100 \mathrm{~km}$ for the same time interval as Fig. 1. The Lomb-Scargle periodogram method (cf. Press and Rybicki, 1989; Hocke, 1998) using an oversampling factor of 4 was applied. From Fig. 2, a component with a period of about $4 \mathrm{~h}$ is found to be dominant below $90 \mathrm{~km}$, while at $100 \mathrm{~km}$ a component of about $8 \mathrm{~h}$ is significant. The amplitude of the $4 \mathrm{~h}$ component reached a maximum at $86 \mathrm{~km}$ with a value of $\sim 15 \mathrm{~K}$. It should be pointed out that the $8 \mathrm{~h}$ temporal variation found at $100 \mathrm{~km}$ is probably not a real periodic component because no clear temporal variation of the temperature between 16:30 and 21:00 UT above $95 \mathrm{~km}$ is seen in Fig. 1a. When we analyzed temperature data for two time intervals separately between 16:30 and 20:30 UT and between 20:30 and 24:30 UT, no salient periodic variation of the temperature was found for the earlier interval above $95 \mathrm{~km}$, while a $4 \mathrm{~h}$ variation component was found for the latter interval.

Figure 3 shows nighttime temporal variations of eastward (a) and northward (b) wind velocities observed with the MR from 16:30 to 24:30 UT. MR wind measurement above $100 \mathrm{~km}$ is rather difficult, and therefore we present only the wind velocity from 80 to $100 \mathrm{~km}$. The zonal wind blew eastward above $92 \mathrm{~km}$ over the interval with a maximum velocity of about $60 \mathrm{~m} \mathrm{~s}^{-1}$. The eastward wind, however, did not show dramatic changes before and after 21:00 UT. On the other hand, the meridional wind velocity varied from $-30 \mathrm{~m} \mathrm{~s}^{-1}$ (southward) to $40 \mathrm{~m} \mathrm{~s}^{-1}$ (northward). The northward wind 
(a)

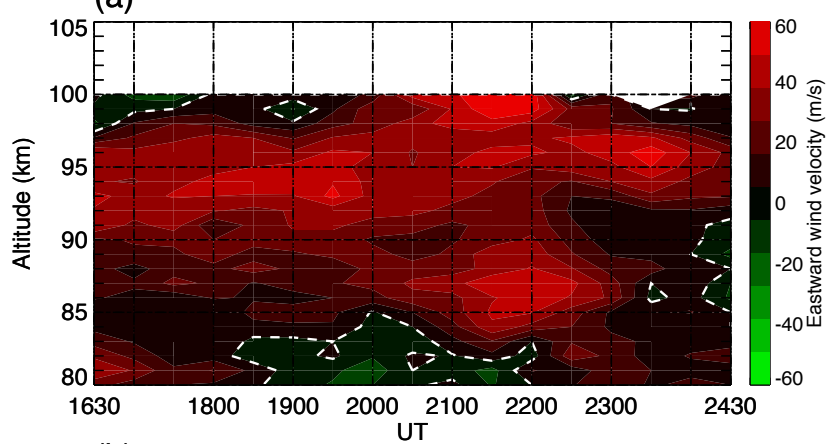

(b)

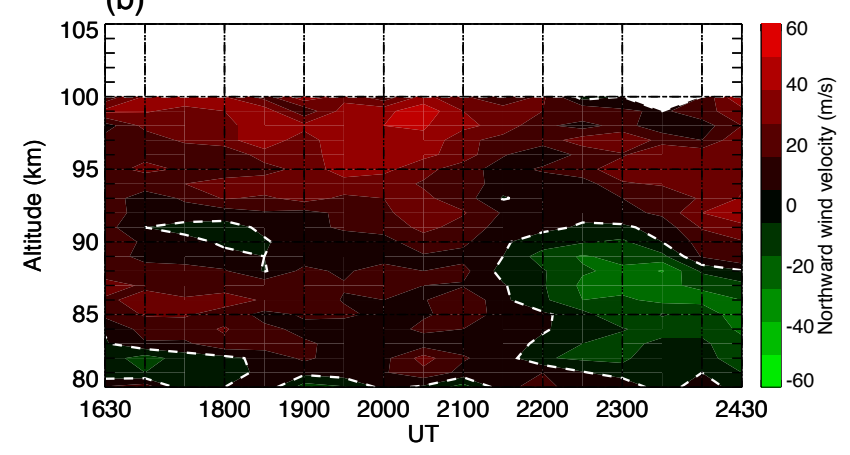

Figure 3. The eastward (a) and northward (b) wind velocity obtained by meteor radar from 80 to $100 \mathrm{~km}$ from 16:30 to 24:30 UT on 29 October 2010. White dashed lines indicate zero wind velocity.

speed became lower after 21:00 UT above $90 \mathrm{~km}$, and the wind direction changed from north to south around 21:30 UT below $\sim 90 \mathrm{~km}$.

\section{Discussion}

We will investigate how the GW disappeared around $95 \mathrm{~km}$ before 21:00 UT by evaluating three mechanisms: criticallevel filtering and convective and dynamic instabilities. If critical-level filtering prevents a GW from achieving upward propagation, the background wind velocity must be equal to or larger than the horizontal phase velocity of the GW. The square of the Brunt-Väisälä frequency should become negative in the height region if a GW is dissipated by convective instabilities. The square of the Brunt-Väisälä frequency, $N^{2}$, is expressed by

$N^{2}=\frac{g}{T}\left(\frac{\mathrm{d} T}{\mathrm{~d} z}+\Gamma_{\mathrm{d}}\right)$,

where $g, T, z$, and $\Gamma_{\mathrm{d}}$ are the acceleration of gravity $\left(9.5 \mathrm{~m} \mathrm{~s}^{-2}\right)$, neutral temperature, altitude, and adiabatic lapse rate in dry air $\left(9.5 \times 10^{-3} \mathrm{~K} \mathrm{~m}^{-1}\right)$. The (bulk) Richardson number is calculated from the following formula:

$R i=\frac{N^{2}}{\left(\frac{\mathrm{d} u}{\mathrm{~d} z}\right)^{2}+\left(\frac{\mathrm{d} v}{\mathrm{~d} z}\right)^{2}}$, where $\frac{\mathrm{d} u}{\mathrm{~d} z}$ and $\frac{\mathrm{d} v}{\mathrm{~d} z}$ are differential eastward and northward wind velocities, respectively. One of the dynamical instabilities in the atmosphere is the Kelvin-Helmholtz $(\mathrm{KH})$ instability, which sets in when the Richardson number $(R i)$ of the wind profile is less than 0.25 (Drazin, 1958), whereas $R i<1$ describes conditions still favorable to the instability persisting (cf. Szewczyk et al., 2013).

\subsection{Critical-level filtering}

We have derived horizontal phase velocity, vertical and horizontal wave numbers and propagating direction of the GW from the LIDAR temperature data as well as the MR wind data using the hodograph method (Sawyer, 1961). The dispersion relation, on the assumption that the Boussinesq approximation can be applied for GWs, is shown as

$\sigma=k(c-U)=\left(\frac{f^{2} m^{2}+N^{2} k^{2}}{k^{2}+m^{2}}\right)^{1 / 2}$,

where $\sigma$ is intrinsic frequency, $k$ is horizontal wave number, $c$ is the phase velocity of the GW, $U$ is the background wind speed along with the propagation direction of the GW, $f$ is the inertia frequency $\left(f=1.36 \times 10^{-4} \mathrm{rad} \mathrm{s}^{-1}\right.$ at Troms $\left.\varnothing\right)$, and $m$ is the vertical wave number of the GW. The altitude region where $c$ equals $U$ is called the critical level, and GW cannot propagate to altitudes above the critical level. This is known as critical-level filtering (cf. Ejiri et al., 2009; Suzuki et al., 2009; Taylor et al., 1993).

The hodograph method is based on the linear theory for GWs (cf. Placke et al., 2013) and has been used to determine the propagation direction as well as phase velocity of GWs (e.g., Yamamoto et al., 1987; Namboothiri et al., 1996). For a monochromatic wave, an ellipse can be drawn. The major axis of the ellipse indicates the propagation direction, and the direction of rotation as a function of height (from lower height to upper height) indicates the direction of energy transport. The upward propagation of GWs observed in the Northern Hemisphere is subject to a clockwise rotation. Intrinsic frequency of a GW can be obtained from the polarization relation

$\sigma=\frac{\tilde{u}}{\tilde{v}} f$,

where $\tilde{u}$ and $\tilde{v}$ are lengths of the major and minor axes, respectively.

The dispersion relation can be obtained from Eq. (3) when solved for horizontal wave number $(k)$ :

$k^{2}=\frac{f^{2}-\sigma^{2}}{\sigma^{2}-N^{2}} m^{2}$.

The vertical wave number $(m)$ can be derived by the hodograph method, and $N^{2}$ can be calculated from the LIDAR temperature data as a function of altitude and time using Eq. (1). Phase velocity is given as follows:

$c=\frac{\omega}{k}$, 

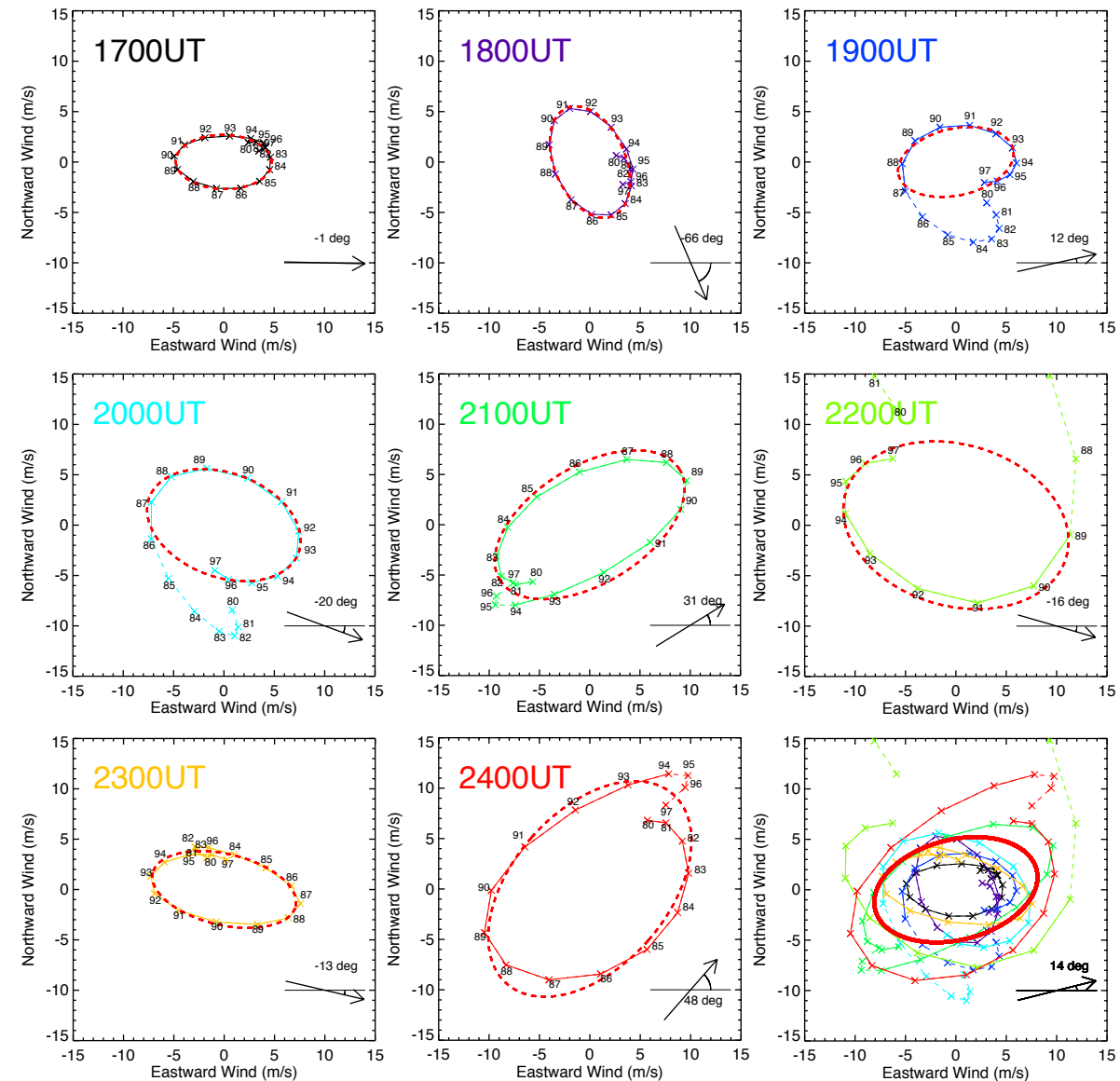

Figure 4. Eight hourly hodographs associated with the fitted eclipses are shown. Crosses denote data values associated with corresponding height values (in $\mathrm{km}$ ). In the bottom right panel, superimposed hodographs with the fitted ellipse (thicker solid line) are presented. The estimated propagation direction is illustrated in each panel.

where $\omega$ is the apparent frequency, and $\omega=4.36 \times$ $10^{-4} \mathrm{rad} \mathrm{s}^{-1}$ (i.e., $2 \pi / 4 \mathrm{~h}$ ) in this event. By using the hodograph method, and Eqs. (4), (5), and (6), we can derive the phase velocity along the propagation direction of the GW.

The hodograph method works properly only for a monochromatic wave event (cf. Lue and Kuo, 2012). It should be pointed out that for the four winter observations of the sodium LIDAR at Troms $\varnothing$, from October 2010 to March 2014, the current event is one of the most prominent monochromatic wave events. In addition, geomagnetically, it was a very quiet interval (Kp less than 1$)$; thus, this event is a rare case. For the hodograph analysis, we use MR wind data obtained over $48 \mathrm{~h}$ from 00:00 UT on 29 October to 24:00 UT on 30 October 2010. First, the mean wind over periodic components that are $48 \mathrm{~h}$ and longer (longer than $8 \mathrm{~h}$ ) and which are derived by the Lomb-Scargle periodogram method using an oversampling factor of 4 is removed from the wind data. Second, using the $8 \mathrm{~h}$ length of wind data from 16:30 to 24:30 UT on 29 October 2010, periodic components are derived by the Lomb-Scargle periodogram method using an oversampling factor of 4 , and then shorter components (shorter than $3 \mathrm{~h}$ ) are removed from the wind data. Third, a similar procedure is applied for the altitude domain from 80 to $97 \mathrm{~km}$. Then, components utilized for the hodograph analysis that have periods of 3 to $8 \mathrm{~h}$ and whose vertical wavelength is longer than $7.5 \mathrm{~km}$ are selected from the data sets.

Figure 4 shows eight sets of hourly hodographs (solid lines) from 17:00 to 24:00 UT. Data values (shown by crosses) together with corresponding height values are illustrated. Furthermore, ellipses (red dashed lines) derived by the least-squares fit and estimated propagation directions are presented in each panel. Some other periodic components seem to be mixed in the hodographs at 19:00, 20:00, and 22:00 UT at lower heights, and we have only used data values at and above 87,86 , and $89 \mathrm{~km}$ for the respective times. Given the $180^{\circ}$ ambiguity, we can conclude that the GW propagated toward east-northeast/east-southeast or west-southwest/westnorthwest.

In the bottom right panel, all the eight hodographs together with an ellipse (thick red solid line) are illustrated, and the ellipse is obtained by the least-squares fit of the eight hodographs using the following method. The upward 
GW propagation can be divided into two components - eastwest and north-south - that are expressed by the apparent frequency $(\omega)$, the vertical wave number $(m)$, the phase $(\phi)$ of the retrieved wave component, and the propagation direction angle $(\theta)$ counted clockwise from east. The following equations are utilized to derive the ellipse:

$$
\begin{aligned}
U_{\text {east }} & =\tilde{u} \cos (\omega t-m z-\phi) \cos \theta \\
& -\tilde{v} \sin (\omega t-m z-\phi) \sin \theta, \\
U_{\text {north }} & =\tilde{u} \cos (\omega t-m z-\phi) \sin \theta \\
& -\tilde{v} \sin (\omega t-m z-\phi) \cos \theta .
\end{aligned}
$$

The major and minor axes of the fitted hodograph (i.e., the ellipse) are 16.5 and $9.95 \mathrm{~m} \mathrm{~s}^{-1}$, respectively. The propagation direction is $14^{\circ}$ north (south) from east (west), i.e., almost eastward or westward. The estimated vertical wavelength is about $11.9 \mathrm{~km}$. By substituting the major and minor axes and the inertial frequency, Eq. (4) gives the intrinsic frequency of the gravity wave, $\sigma$, as $2.26 \times 10^{-4} \mathrm{rad} \mathrm{s}^{-1}$, which corresponds to an oscillation period of $\sim 7.7 \mathrm{~h}$. The square of the Brunt-Väisälä frequency, $N^{2}$, is $4.41 \times 10^{-4} \mathrm{rad}^{2} \mathrm{~s}^{-2}$ (i.e., the Brunt-Väisälä period being about $5 \mathrm{~min}$ ) on average (negative values were rejected) between 81 and $95 \mathrm{~km}$ from 16:30 to 24:30 UT. Thus, Eq. (5) gives the horizontal wave number $(k)$, i.e., $4.56 \times 10^{-6} \mathrm{rad} \mathrm{m}^{-1}$, which corresponds to the horizontal wavelength of $\sim 1379 \mathrm{~km}$. Therefore, the horizontal phase velocity, $c$, is calculated to be $96 \mathrm{~m} \mathrm{~s}^{-1}$ by Eq. (6).

All parameters derived from the hodograph method are listed in Table 1. Since the intrinsic frequency is less than apparent frequency, the propagation direction is likely almost eastward. The maximum wind velocity along the estimated propagation direction during the $8 \mathrm{~h}$ is $51 \mathrm{~m} \mathrm{~s}^{-1}$, which is significantly less than $c\left(96 \mathrm{~m} \mathrm{~s}^{-1}\right)$. Furthermore, as shown in Table 1 , the differences $(c-U)$ for the hourly results are always positive. These results indicate that the phase velocity $c$ was always greater than the background wind velocity $U$. Therefore, we conclude that critical-level filtering was not a dominant mechanism for the GW disappearing in this event.

Another point to be investigated is the similarity of wavelike structures measured with the LIDAR and the MR. Since physical parameters provided with the two instruments differ, to ensure both instruments captured the same GW, we should investigate the relationship below:

$\tilde{\theta}\left(=\frac{\theta^{\prime}}{\bar{\theta}}\right)=i \frac{N^{2}}{g \sigma} \frac{k}{m} u^{\prime}$,

where $\tilde{\theta}$ is proportion of the fluctuation of the potential temperature, $\bar{\theta}$ and $i$ are the potential temperature and imaginary unit, and $\theta^{\prime}$ and $u^{\prime}$ are perturbations of potential temperature and wind velocity along the propagation direction, respectively (cf. Fritts and Alexander, 2003). Here, we use the MR wind data obtained for the same interval as the LIDAR temperature data from 16:30 to 24:30 UT on 29 October 2010,
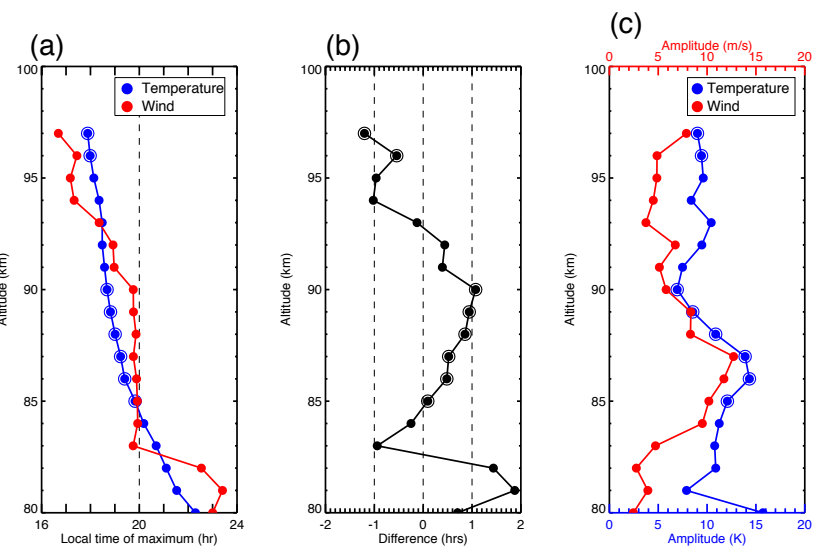

Figure 5. The local time maximum (a), phase difference between temperature and wind oscillation (b), and amplitude profile of the temperature and wind (c). The red and blue circles denote wind and temperature data, respectively. The period is $4 \mathrm{~h}$. The double circles show values over the $99 \%$ significance level.

and $u^{\prime}=13 \mathrm{~m} \mathrm{~s}^{-1}$ at $87 \mathrm{~km}$ (from Fig. 5c). By using the parameter values above, we obtain

$\tilde{\theta}=\sim 0.023$.

This estimation suggests that perturbation of the background temperature due to the GW should be $\sim 2.3 \%$. The averaged temperature over the $8 \mathrm{~h}$ is $\sim 216 \mathrm{~K}$ at $87 \mathrm{~km}$, and then the temperature perturbation is calculated to be $\sim 5.0 \mathrm{~K}$ $(=0.023 \times 216)$, which is about $40 \%$ of the amplitude observed by the LIDAR (see Fig. 5c).

According to Eq. (9), the phase of the GW in the temperature should precede by $90^{\circ}$ that of the wind along the propagation direction (i.e., $1 \mathrm{~h}$ for the oscillation period of $4 \mathrm{~h}$ ). Figure 5a shows height profiles of the phases of the temperature and the wind for the GW (with an apparent period of $4 \mathrm{~h}$ ) along its propagation direction, and Fig. 5b shows their differences. Figure $5 \mathrm{c}$ shows height profiles of the amplitudes of the temperature (blue) and the wind (red) data. Blue double circles denote the values whose normalized amplitudes are greater than the corresponding $99 \%$ significance levels, and they are located between 85 and $90 \mathrm{~km}$ and between 96 and $97 \mathrm{~km}$. The phase difference between 85 and $90 \mathrm{~km}$ presented in Fig. $5 \mathrm{~b}$ shows that phases of the temperature preceded that of the wind by about $0-1 \mathrm{~h}$. When we consider worse temporal resolution of the MR $(1 \mathrm{~h})$ wind measurements, these results confirm that the LIDAR and the MR have captured the same GW signature.

\subsection{Convective and dynamic instabilities}

GWs dissipate their energy due to convective instabilities when the background temperature gradient is superadiabatic (Hodges Jr., 1967). The Brunt-Väisälä frequency can be used as an indicator of the convective instability. Figure 6 shows the square of Brunt-Väisälä frequencies, derived by Eq. (1), 
Table 1. Parameters derived with the hodograph method.

\begin{tabular}{lrrrrrr}
\hline Time $(\mathrm{UT})$ & $\bar{u}\left(\mathrm{~m} \mathrm{~s}^{-1}\right)$ & $\bar{v}\left(\mathrm{~m} \mathrm{~s}^{-1}\right)$ & $\theta(\mathrm{rad})$ & $c\left(\mathrm{~m} \mathrm{~s}^{-1}\right)$ & $U\left(\mathrm{~m} \mathrm{~s}^{-1}\right)$ & $c-U\left(\mathrm{~m} \mathrm{~s}^{-1}\right)$ \\
\hline $17: 00$ & 9.51 & 5.37 & -0.02 & 88.6 & 38.1 & 50 \\
$18: 00$ & 11.6 & 7.07 & -1.17 & 95.2 & 39.2 & 56 \\
$19: 00$ & 11.6 & 6.63 & 0.22 & 86.2 & 45.4 & 40 \\
$20: 00$ & 15.8 & 10.3 & -0.35 & 100 & 50.3 & 50 \\
$21: 00$ & 21.0 & 11.7 & 0.55 & 83.6 & 51.9 & 32 \\
$22: 00$ & 22.8 & 16.0 & -0.28 & 127 & 47.9 & 79 \\
$23: 00$ & 14.6 & 7.06 & -0.23 & 75.9 & 51.0 & 25 \\
$24: 00$ & 25.0 & 15.4 & 0.85 & 98.5 & 37.6 & 61 \\
\hline All & 16.5 & 9.95 & 0.24 & 95.8 & 51.3 & 45 \\
\hline
\end{tabular}

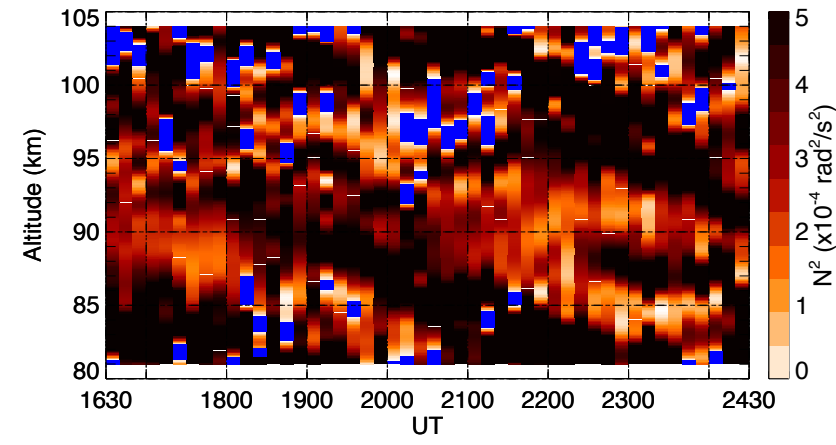

Figure 6. Variations of the square of Brunt-Väisälä frequencies $\left(N^{2}\right)$ from 16:30 to 24:30 UT between 81 and $104 \mathrm{~km}$. Negative $N^{2}$ regions are shown by blue filled squares.

from $16: 30$ to $24: 30 \mathrm{UT}$ between 81 and $104 \mathrm{~km}$. Negative $\left(N^{2}<0\right)$ regions are shown by blue filled squares. The vertical temperature gradient, $\mathrm{d} T / \mathrm{d} z$, is calculated using neighbor data within $\pm 1 \mathrm{~km}$ height. Below $87 \mathrm{~km}$, there is a tendency for the number of negative regions to be larger before 21:00 UT than those after 21:00 UT, while between 87 and $94 \mathrm{~km} N^{2}$ is almost always positive over the time interval. Between 95 and $100 \mathrm{~km}, N^{2}$ is lower before 21:00 UT than after 21:00 UT. Furthermore, there is a tendency for the negative values to occur more frequently before 21:00 UT than after 21:00 UT between 95 and $100 \mathrm{~km}$.

Figure 7a shows variations of the Richardson number from Eq. (2), and Fig. 7b shows their error values. More precisely, this $R i$ should be called the bulk Richardson number, but, as in many other studies, we call it the Richardson number in this paper. The error values are calculated based on the propagation of uncertainties, and they are less than 0.5 for almost the whole time interval. Between 16:30 and 21:30 UT, there is an almost continual layer (about a few $\mathrm{km}$ thick) where the Richardson number is less than 2 (including negative values) between 95 and $99 \mathrm{~km}$. The value of $0<R i<0.25$ occurred rarely, but it occurred between 18:50 and 19:40 UT around $97-98 \mathrm{~km}$. Since the almost all-sky horizontal view $\left(\sim 140^{\circ}\right)$ as well as poor height $(2 \mathrm{~km})$ and temporal $(1 \mathrm{~h})$ resolution
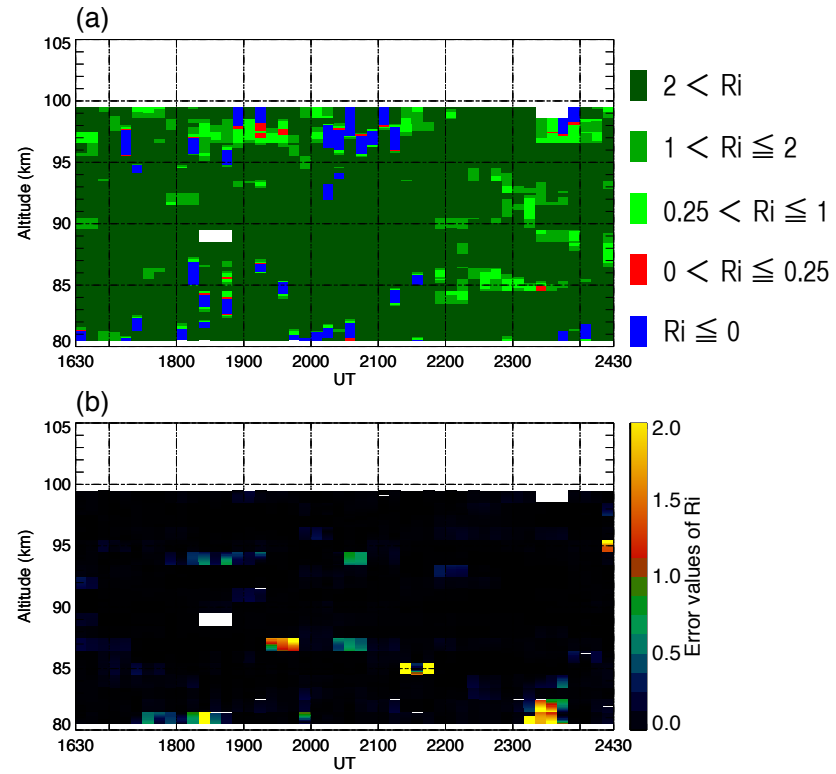

Figure 7. (a) Variations of the Richardson number from 81 to $99 \mathrm{~km}$ between 16:30 and 24:30 UT on 29 October 2010. Negative values are shown by blue filled squares. (b) Error values of the Richardson number.

of the MR induces overestimation of $R i$, we are able to say that the shear instability occurred more frequently than the current occurrence of $0<R i<0.25$.

\subsection{GW breaking}

Atmospheric instabilities and GW breaking/saturation result in turbulence and irregularities of the electron density. The backscatter echo power of MF radars depends on turbulence and sharp gradients of the electron density. Thus, the echo power can be used as a proxy of turbulent regions (cf. Thrane et al., 1987). The observations were made during a very geomagnetically quiet interval; thus, the influence of auroral particle precipitations would be negligible. Figure 8 shows height-time variations of the backscatter echo power from 16:30 and 24:30 UT on 29 October 2010 together with 


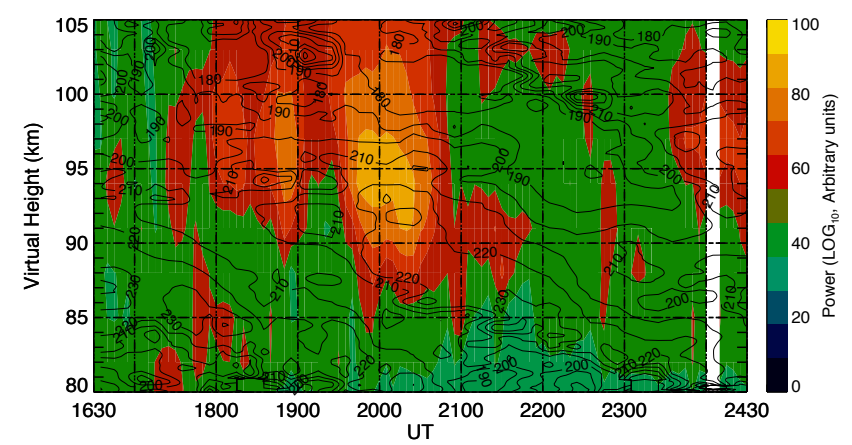

Figure 8. Variations of MF radar echo intensity from 80 to $105 \mathrm{~km}$ (in virtual height) between 16:30 and 24:30 UT on 29 October 2010. The black lines are contours of the neutral temperature $(\mathrm{K})$ shown in Fig. 1a.

contour lines of the neutral temperature shown in Fig. 1a. Enhancements of the backscatter echo power are found from 18:00 to 21:00 UT above about $90 \mathrm{~km}$, and the echo power decreased sharply after 21:00UT. This suggests the presence of strong turbulence above $90-95 \mathrm{~km}$ between 18:00 and 21:00 UT. This region corresponds to the region where the Brunt-Väisälä frequency became lower and $R i$ was lower.

Figure 9 shows the sodium mixing ratio as a function of altitude and time together with potential temperature between 16:30 and 24:30 UT on 29 October 2010. The mixing ratio was calculated in the same way as in the work of Williams et al. (2002), where the measured temperature was utilized to determine the total air density based on hydrostatic relation and ideal gas law (cf. Liu et al., 2004). Potential temperature is defined as $T(t, z)\left(p\left(t_{0}, z_{0}\right) / p(t, z)\right)^{\kappa}$, where $T(t, z)$ is neutral temperature obtained by LIDAR as a function of time $(t)$ and altitude $(z), \kappa$ is the index of potential temperature $(=2 / 7), p(t, z)$ is pressure as a function of time and altitude, and $t_{0}$ and $z_{0}$ are the reference time and altitude determined to be $20: 30 \mathrm{UT}$ and $81 \mathrm{~km}$, respectively. $p\left(t_{0}, z_{0}\right)$ is given by

$p\left(t_{0}, z_{0}\right)=n\left(t_{0}, z_{0}\right) k_{\mathrm{b}} \bar{T}\left(z_{0}\right)$,

where $n\left(t_{0}, z_{0}\right)$ is given by MSIS-E-90 model (Hedin, 1991) and $k_{\mathrm{b}}$ is the Boltzmann constant $\left(=1.38 \times 10^{-23} \mathrm{~J} \mathrm{~K}^{-1}\right)$. $\bar{T}\left(z_{0}\right)$ ( $\left.=206 \mathrm{~K}\right)$ is the average value of the observed temperatures over the $8 \mathrm{~h}$ at $81 \mathrm{~km}$. By assuming the hydrostatic equilibrium, we can calculate the pressure as follows:

$p(t, z)=p\left(t_{0}, z_{0}\right) \exp \left(-\frac{g}{R} \int_{z_{0}}^{z} T(t, h)^{-1} \mathrm{~d} h\right)$,

where $R\left(=287 \mathrm{~J} \mathrm{~kg}^{-1} \mathrm{~K}^{-1}\right)$ is the gas constant (cf. Williams et al., 2002). The atmospheric number density is then calculated from the ideal gas law:

$n(t, z)=\frac{p(t, z)}{k_{\mathrm{b}} T(t, z)}$.

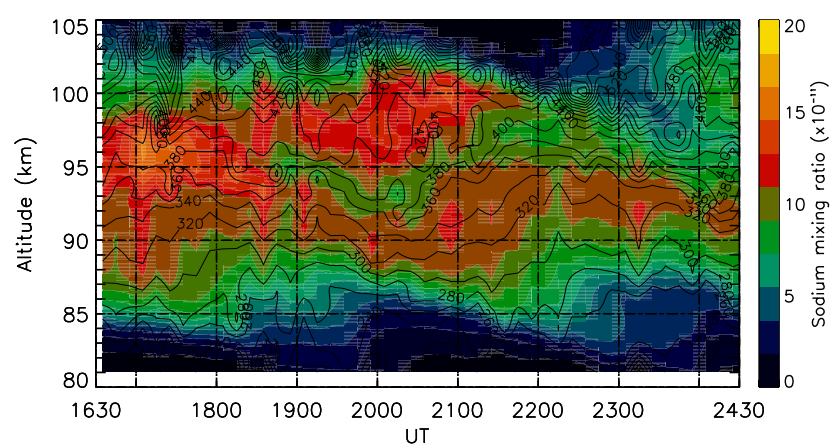

Figure 9. The color contours show the sodium mixing ratio $\left(\times 10^{-11}\right)$ on 29 October 2010 . The black lines are contours of the potential temperature $(\mathrm{K})$.

The sodium mixing ratio shows a double peak structure between 18:00 and 21:30 UT. An overturning in the sodium altitude profile should indicate that a wave is breaking or is about to break (Hecht, 2004). Possible causes of overturning features of the sodium density between 95 and $105 \mathrm{~km}$ were discussed by Larsen et al. (2004). Though the causes are still not well understood, an overturning is a common characteristic of Kelvin-Helmholtz instabilities associated with large shears or the manifestation of GW breaking (Larsen et al., 2004).

To summarize the observational results, the region of the lower Richardson number above $95 \mathrm{~km}$ corresponds relatively well to regions of enhancements of MF radar echo power as well as to the overturning structure of the sodium mixing ratio. Therefore, the dissipation of the GW around $95 \mathrm{~km}$ before 21:00 UT would probably be due to wave breaking and the instabilities.

\subsection{Possible causes of the difference of the GW propagation}

Finally, we will briefly discuss what caused the difference between the two intervals, that is to say, why the GW did not dissipate after about 21:00 UT. We already demonstrated that the zonal wind, almost parallel to the wave propagation direction, did not change much, while the meridional wind changed direction below $91 \mathrm{~km}$ between the intervals, showing a more southward direction after 21:30 UT. The greater change in the meridional wind, however, did not occur above $90 \mathrm{~km}$; thus, it is not be a major candidate mechanisms for the GW dissipating above $95 \mathrm{~km}$. The semidiurnal tide is a dominant source of changing the wind and temperature in the polar upper mesosphere and lower thermosphere and reduces the stability on the topside of the positive temperature perturbation (cf. Zhao et al., 2003). We have derived semidiurnal tidal amplitude and phase using $48 \mathrm{~h}$ MR wind data obtained from 00:00 UT on 29 October and 24:00 UT on 30 October 2010 by using the Lomb-Scargle periodogram method, and we present them in Fig. 10. The semidiurnal 

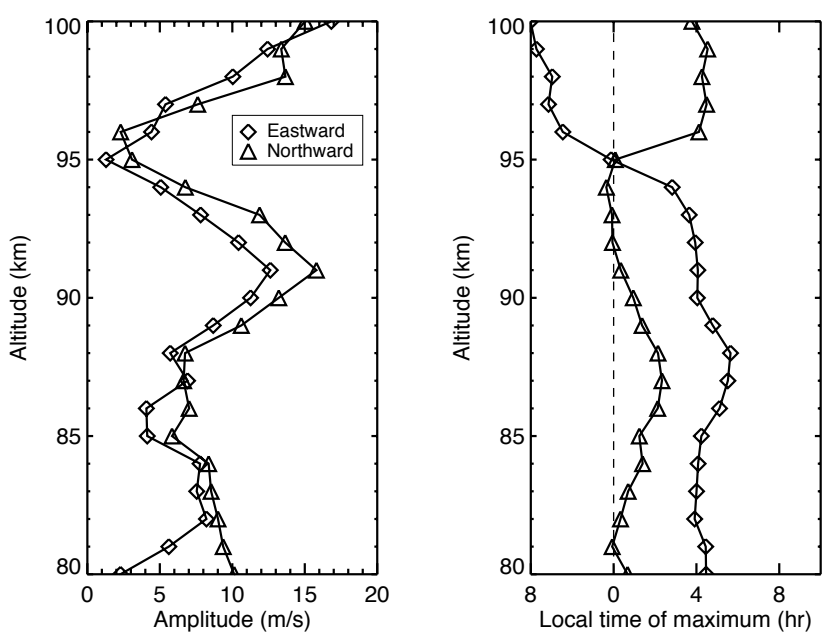

Figure 10. Altitude profiles of semidiurnal tidal amplitude (left) and local time of maximum (right). Diamonds and triangles denote eastward and northward components, respectively.

tidal amplitudes reached a maximum at $91 \mathrm{~km}$ for both the meridional and zonal components with values of $\sim 16$ and $\sim 13 \mathrm{~m} \mathrm{~s}^{-1}$, respectively, and minimized at $95-96 \mathrm{~km}$. Since the phase jump is seen around $95 \mathrm{~km}$, it appears that another mode grew above $95 \mathrm{~km}$. Around $95 \mathrm{~km}$, the semidiurnal tidal amplitudes were very small, and thus it seems that the semidiurnal tide did not significantly influence the GW propagation.

Figure 11 compares background conditions between the two intervals before and after 21:00 UT. In the top panel, altitude profiles of the averaged temperature are compared, and it is found that the shapes of them differ. In particular, between 94 and $100 \mathrm{~km}$, the negative temperature gradient $\left(-4.4 \mathrm{~K} \mathrm{~km}^{-1}\right)$ existed before 21:00 UT, while after 21:00 UT the temperature was relatively constant (associated with small fluctuations) by height. This suggests that the atmosphere before 21:00 UT tended to become unstable more easily due to wave-induced temperature oscillation than in the later interval. In the middle panel, the neutral densities derived by Eq. (13) are presented for comparison. The averaged neutral density before 21:00 UT is larger than that after 21:00 UT above $95 \mathrm{~km}$, while between 85 and $95 \mathrm{~km}$ the opposite is true. The difference is presented more clearly in Fig. 11c. In the bottom panel, the ratio of the neutral densities (thick line) as well as the pressure (thin line) derived by Eq. (12) are presented. Between 85 and $95 \mathrm{~km}$ the averaged neutral density was larger by up to $\sim 3 \%$ after 21:00 UT, while between 95 and $100 \mathrm{~km}$ it is larger by up to $\sim 10 \%$ before 21:00 UT. The ratio of the pressure shows that higher pressure occurred above $87 \mathrm{~km}$ before 21:00 UT.

To summarize, during the earlier interval (i.e., before 21:00 UT), the neutral density and the pressure were higher - up to $\sim 10$ and $\sim 7 \%$ above 95 and $87 \mathrm{~km}$, respectively - and the steady negative slope of the temperature gradient

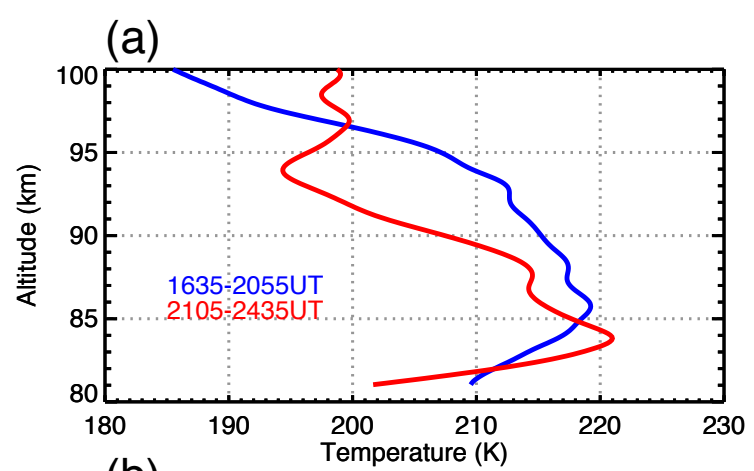

(b)

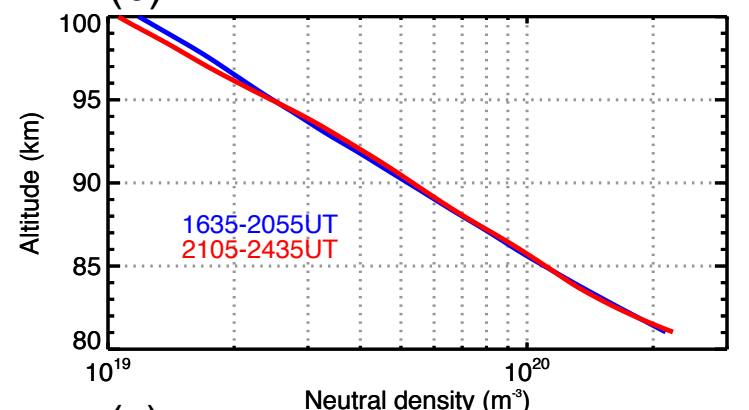

(c)

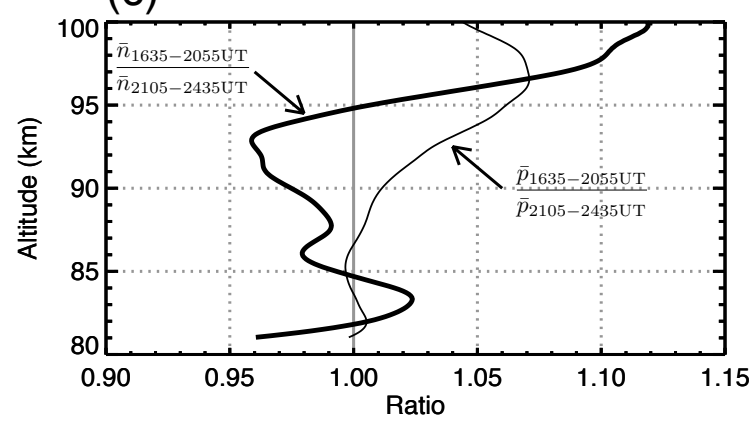

Figure 11. (a) Altitude profiles of the background temperature are compared for the two intervals between 16:30 and 21:00 UT and 21:00 and 24:30 UT. (b) Same as (a) but for the neutral density. (c) Ratios of neutral density (thick line) and pressure (thin line) between the two intervals.

existed above $94 \mathrm{~km}$. It appears that these different background conditions would cause the difference of the GW propagation. We would suggest that, before 21:00 UT between 85 and $94 \mathrm{~km}$, the GW amplitude grew more significantly with increasing height than in the latter interval, that the GW reached around $95 \mathrm{~km}$ where the steeper negative temperature slope existed, and that the GW then broke down, generating the strong turbulence observed by MF radar. On the other hand, after 21:00 UT, the growth of GW amplitude was less below $95 \mathrm{~km}$, and the background atmosphere was more stable (no negative temperature gradient) above $95 \mathrm{~km}$ and allowed the GW to propagate to upper heights. 


\section{Summary}

A monochromatic GW was observed on 29 October 2010 with the sodium LIDAR operated at Ramjordmoen, Troms $\varnothing$, Norway $\left(69.6^{\circ} \mathrm{N}, 19.2^{\circ} \mathrm{E}\right)$. The observational data were obtained during a geomagnetically very quiet interval $(\mathrm{Kp} \leq 1)$. The spectral as well as the hodograph analyses indicated that apparent period, intrinsic period, vertical and horizontal wavelengths, and maximum amplitude were $4 \mathrm{~h}, \sim 7.7 \mathrm{~h}$, $\sim 11.9 \mathrm{~km}, \sim 1.38 \times 10^{3} \mathrm{~km}$, and $\sim 15 \mathrm{~K}$, respectively, from 81 to $95 \mathrm{~km}$. The GW dissipated at $\sim 95 \mathrm{~km}$ height from 16:30 to $\sim 21: 00 \mathrm{UT}$, while the GW propagated further over $100 \mathrm{~km}$ from 21:00 to 24:30 UT. We evaluated three candidate mechanisms for the dissipation of the GW: criticallevel filtering and the convective and dynamic instabilities. To evaluate critical-level filtering, we compared the background wind velocity and the phase velocity derived by the hodograph method. As a result of the analysis, we have found that the phase velocity is almost always greater than the background wind velocity, indicating that critical-level filtering did not play a role in this event. To evaluate the convective and dynamic instabilities, we calculated the BruntVäisälä frequency $(N)$ and Richardson number $(R i)$. Before 21:00 UT and between 95 and $100 \mathrm{~km}, N^{2}$ is lower and the negative $N^{2}$ appears to occur more frequently. There was an almost continual layer a few kilometers thick where the $R i$ is smaller $(\leq 2)$ between 95 and $100 \mathrm{~km}$ before 21:20 UT, implying that the dynamic instabilities would occur, considering poorer height and horizontal and temporal resolutions of the MR wind data. Because we found enhancements of MF radar power echo before 21:00 UT and an overturning structure of the sodium mixing ratio between 18:30 and 21:30 UT, we concluded that the GW dissipated by wave breaking and the instabilities before $\sim 21: 00 \mathrm{UT}$.

We investigated differences of background atmosphere for the two intervals between 16:30 and 21:00 and 21:00 and 24:30 UT. The most prominent difference is that there was a steady negative slope of the averaged temperature $\left(-4.4 \mathrm{~K} \mathrm{~km}^{-1}\right)$ between 94 and $100 \mathrm{~km}$ before 21:00 UT. We propose that the difference in the temperature profile above $94 \mathrm{~km}$ is a probable cause of the change in the GW propagation. We need further data sets to investigate this issue in more detail. Since October 2012, the sodium LIDAR at Troms $\varnothing$ has observed wind data together with neutral temperature and sodium density data along with five directions (usually, vertical, north, south, east, and west). Thus, we can conduct similar studies in the near future but using wind data with higher height and narrower spatial resolution.

Acknowledgements. The Troms $\emptyset$ sodium lidar project is mainly supported by Special Funds for Education and Research (Energy Transport Processes in Geospace) from the Ministry of Education, Culture, Sports, Science, and Technology in Japan (MEXT), in collaboration with Nagoya University, Shinshu University, RIKEN, University of Troms $\varnothing$, and the EISCAT Scientific Association. We wish to thank M. Ejiri and Y. Tomikawa for their valuable comments. We thank K. Hocke for letting us use his Lomb-Scargle periodogram method routines. We also acknowledge the use of geomagnetic data from the World Data Centers for Geomagnetism in Kyoto, Japan, and Copenhagen, Denmark, and the Kp indices from GeoForschungsZentrum Potsdam (www.gfz-potsdam.de). T. Takahashi is supported as a research fellow of the Japan Society for the Promotion of Science (JSPS) for Young Scientists. This research has been partly supported by MEXT through a Grant-in-Aid for JSPS fellows (25-3733), Scientific Research B (22403010, 23340144, 24310010, and 25287126), and Special Funds for Education and Research (Energy Transport Processes in Geospace). This research was also partially supported by MEXT through the Grant-in-Aid for Nagoya University Global COE Program, Quest for Fundamental Principles in the Universe: From Particles to the Solar System and the Cosmos, and Inter-University Upper atmosphere Global Observation NETwork (IUGONET) . This research was also partly supported by the National Institute of Polar Research through General Collaboration Projects no. 24-10. S. Nozawa thanks the International Space Science Institute (ISSI) for sponsoring the team (no. 217) meetings.

Topical Editor C. Jacobi thanks F. J. Mulligan and one anonymous referee for their help in evaluating this paper.

\section{References}

Aso, T., Tsuda, T., and Kato, S.: Meteor radar observations at Kyoto Univ., J. Atmos. Terr. Phys., 41, 517-525, doi:10.1016/00219169(79)90075-8, 1979.

Drazin, P. G.: The stability of a shear layer in an unbounded heterogeneous inviscid fluid, J. Fluid Mech., 4, 214-224, 1958.

Ejiri, M. K., Taylor, M. J., Nakamura, T., and Franke, S. J.: Critical level interaction of a gravity wave with background winds driven by a large-scale wave perturbation, J. Geophys. Res., 114, D18117, doi:10.1029/2008JD011381, 2009.

Fritts, D. C. and Alexander, M. J.: Gravity wave dynamics and effects in the middle atmosphere, Rev. Geophys., 41, 1003, doi:10.1029/2001RG000106, 2003.

Fritts, D. C. and Rastogi, P. K.: Convective and dynamical instabilities due to gravity wave motions in the lower and middle atmosphere: Theory and observations, Radio Sci., 20, 1247-1277, 1985.

Fritts, D. C. and Vadas, S. L.: Gravity wave penetration into the thermosphere: sensitivity to solar cycle variations and mean winds, Ann. Geophys., 26, 3841-3861, doi:10.5194/angeo-263841-2008, 2008.

Hall, C. M.: The Ramfjordmoen MF radar $\left(69^{\circ} \mathrm{N}, 19^{\circ} \mathrm{E}\right)$ : application development 1990-2000, J. Atmos. Sol.-Terr. Phy., 63, 171179, 2001.

Hall, C. M., Aso, T., Tsutsumi, M., Nozawa, S., Manson, A. H., and Meek, C. E.: A comparison of mesosphere and lower thermosphere neutral winds as determined by meteor and medium-frequency radar at $70^{\circ} \mathrm{N}$, Radio Sci., 40, RS4001, doi:10.1029/2004RS003102, 2005.

Hecht, J. H.: Instability layers and airglow imaging, Rev. Geophys., 42, RG1001, doi:10.1029/2003RG000131, 2004.

Hecht, J. H., Walterscheid, R. L., Fritts, D. C., Isler, J. R., Senft, D. C., Gardner, C. S., and Franke, S. J.: Wave breaking signatures in $\mathrm{OH}$ airglow and sodium densities and temperatures 1 . Airglow 
imaging, Na lidar, and MF radar observations, J. Geophys. Res., 102, 6655-6668, 1997.

Hecht, J. H., Liu, A. Z., Walterscheid, R. L., and Rudy, R. J.: Maui Mesosphere and Lower Thermosphere e(Maui MALT) observations of the evolution of Kelvin-Helmholtz billows formed near $86 \mathrm{~km}$ altitude, J. Geophys. Res., 110, D09S10, doi:10.1029/2003JD003908, 2005.

Hedin, A. E.: Extension of the MSIS thermosphere model into the lower atmosphere, J. Geophys. Res., 96, 1159-1172, 1991.

Hocke, K.: Phase estimation with the Lomb-Scargle periodogram method, Ann. Geophys., 16, 356-358, 1998,

http://www.ann-geophys.net/16/356/1998/.

Hodges Jr., R. R.: Generation of turbulence in the upper atmosphere by internal gravity waves, J. Geophys. Res., 72, 34553458, 1967.

Holton, J. R.: The role of gravity wave induced drag and diffusion in the momentum budged of the mesosphere, J. Atmos. Sci., 39, 791-799, 1982.

Larsen, M. F., Liu, A. Z., Gardner, C. S., Kelley, M. C., Collins, S., Friedman, J., and Hecht, J. H.: Observations of overturning in the upper mesosphere and lower thermosphere, J. Geophys. Res., 109, D02S04, doi:10.1029/2002JD003067, 2004.

Li, F., Liu, A. Z., Swenson, G. R., Hecht, J. H., and Robinson, W. A.: Observation of gravity wave breakdown into ripples associated with dynamical instabilities, J. Geophys. Res., 110, D09S11, doi:10.1029/2004JD004849, 2005.

Lindzen, R. S.: Turbulence and stress owing to gravity wave and tidal breakdown, J. Geophys. Res., 86, 9707-9714, doi:10.1029/95JD03299, 1981.

Liu, A. Z., Roble, R. G., Hecht, J. H., Larsen, M. F., and Gardner, C. S.: Unstable layers in the mesopause region observed with Na liar during the Turbulent Oxygen Mixing Experiment (TOMEX) campaign, J. Geophys. Res., 109, D02S02, doi:10.1029/2002JD003056, 2004.

Lu, X., Ziu, A. L., Swenson, G. R., Li, T., Leblac, T., and McDermid, I. S.: Gravity wave propagation and dissipation from the stratosphere to the lower thermosphere, J. Geophys. Res., 114, D11101, doi:10.1029/2008JD010112, 2009.

Lue, H. Y. and Kuo, F. S.: Comparative studies of methods of obtaining AGW's propagation properties, Ann. Geophys., 30, 557570, doi:10.5194/angeo-30-557-2012, 2012.

Meek, C. E.: An efficient method for analysing ionospheric drifts data, J. Atmos. Terr. Phys., 42, 835-839, 1980.

Namboothiri, S. P., Tsuda, T., Tsutsumi, M., Nakamura, T., Nagasawa, C., and Abo, M.: Simultaneous observations of mesospheric gravity waves with the MU radar and a sodium lidar, J. Geophys. Res., 101, 4057-4063, 1996.

Nozawa, S., Kawahara, T. D., Saito, N., Hall, C. M., Tsuda, T. T., Kawabata, T., Wada, S., Brekke, A., Takahashi, T., Fujiwara, H., Ogawa, Y., and Fujii, R.: Variations of the neutral temperature and sodium density between 80 and $107 \mathrm{~km}$ above Troms $\varnothing$ during the winter of 2010-2011 by a new solid state sodium LIDAR, J. Geophys. Res., 119, 441-451, doi:10.1002/2013JA019520, 2014.

Placke, M., Hoffmann, P., Gerding, M., Becker, E., and Rapp, M.: Testing liner gravity wave theory with simultaneous wind and temperature data from the mesosphere, J. Atmos. Terr. Phys., 93, 57-69, 2013.
Press, W. H. and Rybicki, G. B.: Fast algorithm for spectral analysis of unevenly sampled data, Astrophys. J., 338, 277-280, 1989.

Reid, I. M.: On the measurement of gravity waves, tides and mean winds in the low and middle latitude mesosphere and thermosphere with MF radar, Adv. Space Res., 18, 131-140, 1996.

Sawyer, J. S.: Quasi-periodic wind variations with height lower stratosphere, Q. J. Meteorol. Soc., 87, 24-33, 1961.

She, C. Y. and Yu, J. R.: Doppler-free saturation fluorescence spectroscopy of $\mathrm{Na}$ atoms for atmospheric application, Appl. Optics, 34, 1063-1075, 1995.

She, C. Y., Latifi, H., Yu, J. R., Alverez II, R. J., Bills, R. E., and Gardner, C. S.: Two-frequency LIDAR technique for mesospheric Na temperature measurements, Geophys. Res. Lett., 31, L24111, doi:10.1029/2004GL021165, 1990.

Suzuki, S., Shiokawa, K., Hosokawa, K., Nakamura, K., and Hocking, W. K.: Statistical characteristics of polar cap mesospheric gravity waves observed by an all-sky airglow imager at Resolute Bay, Canada, J. Geophys. Res., 114, A01311, doi:10.1029/2008JA013652, 2009.

Szewczyk, A., Strelnikov, B., Rapp, M., Strelnikova, I., Baumgarten, G., Kaifler, N., Dunker, T., and Hoppe, U.-P.: Simultaneous observations of a Mesospheric Inversion Layer and turbulence during the ECOMA-2010 rocket campaign, Ann. Geophys., 31, 775-785, doi:10.5194/angeo-31-775-2013, 2013.

Taylor, M. J., Ryan, E. H., Tuan, T. F., and Edwards, R.: Evidence of preferential directions for gravity wave propagation due to wind filtering in the middle atmosphere, J. Geophys. Res., 98, 60476057, 1993.

Thrane, E. V., Blix, T. A., Hall, C., Hansen, T. L., von Zahn, U., Meyer, W., Czechowsky, P., Schmidt, G., Widdel, H.-U., and Neumann, A.: Small scale structure and turbulence in the mesosphere and lower thermosphere at high latitude in winter, J. Atmos. Terr. Phys., 46, 119-128, 1987.

Tsutsumi, M., Holdsworth, D., Nakamura, T., and Reid, I.: Meteor observations with an MF radar, Earth Planets Space, 51, 691699, 1999.

Vadas, S. L. and Fritts, D. C.: Thermosphere responses to gravity waves arising from mesoscale convective complexes, J. Atmos. Sol.-Terr. Phy., 66, 781-804, 2004.

Williams, B. P., White, M. A., Kruger, D. A., and She, C. Y.: Observation of a large amplitude wave and inversion layer leading to convective instability in the mesopause region over Fort Collins, CO (41N, 105W), Geophys. Res. Lett., 29, 1850, doi:10.1029/2001GL014514, 2002.

Yamamoto, M., Tsuda, T., Kato, S., Sato, T., and Fukao, S.: A Saturated inertia gravity wave in the Mesosphere Observed by the Middle and Upper atmosphere radar, J. Geophys. Res., 92, 11993-11999, 1987.

Zhao, Y., Liu, A. Z., and Gardner, C. S.: Measurements of atmospheric stability in the mesopause region at starfire optical range, NM, J. Atmos. Sol.-Terr. Phy., 65, 219-232, 2003. 